\section{考文 嗝}

[1] Gao Shian, Comment. Math. Univ. Sancti Pewli, 38(1989) 1:11-20.
陈宗媗

（南昌职业技术师范学院数学系, 青量330013）

高宗升

（河南师范大学数学系, 新乡 453002）

\title{
生理 $\mathrm{pH}$ 值下稳定的水溶二茂钛体系*
}

二氞二茂钎及其衍生物具有抗癌活性已 引起人们的关注 ${ }^{[1]}$, 寻求水溶性、并且能稳定 存在的体系是极有意义和吸引力的工作 ${ }^{[2]}$. 本文报道首例能在生理 $\mathrm{pH}$ 值下稳定存在的 水溶体系 $\mathrm{Cp}_{2} \mathrm{TiCl}_{2}$-乙酰丙酮 $-\mathrm{H}_{2} \mathrm{O}$.

水溶性 $\mathrm{Cp}_{2} \mathrm{TiCl}_{2}$-乙酰丙酮 $-\mathrm{H}_{2} \mathrm{O}$ 体系 的原位 ${ }^{1} \mathrm{H}-\mathrm{NMR}$ 和 ${ }^{13} \mathrm{C}-\mathrm{NMR}$ 研究表明该 体系存在下面三种物种:<smiles></smiles>

(I)

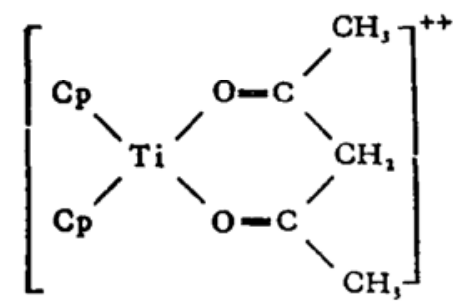

(II)

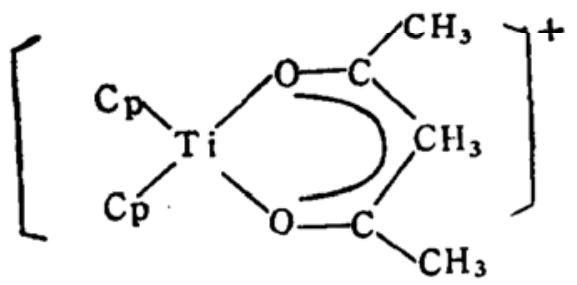

(III)

利用 ${ }^{1} \mathrm{H}-\mathrm{NMR}$ 技术考察了该水溶体系的各 物种 (I-III) 在不同 $\mathrm{pH}$ 值下稳定性,结果 表明物种(I)和(II)随溶液的酸度降低, 所占
比例下降; 当溶液 $\mathrm{pH}$ 值为 5 . 后, 物种 (III) 占据主要成分. 更富有意义的在于当溶液的 $\mathrm{pH}$ 值为 7 时, 即在生理 $\mathrm{pH}$ 值条件下, 环戊 二烯基质子信号仍然存在, 表明了该水溶性 体系能够在生理 $\mathrm{pH}$ 值下保持 “ $\mathrm{Cp}_{2} \mathrm{Ti}^{\mathrm{T}}$ ” 团, 这是第一例水溶性体系具有很强稳定性. 进一步用紫外光谱考察该水溶体系的稀溶液 在不同酸度下物种变化情况, 其结果与 ' $\mathrm{H}-$ NMR 相吻合. 该体系这一稳定特性预示着 物种(I)可能是抗癌活性物种, 而乙酰丙酮起 到对溶液的酸度改变的抑制作用从而使该体 系在较强 $\mathrm{pH}$ 值下能够稳定存在. 该水溶性 体系提供了研究水溶性茂钛与生物活性物种 作用的可能, 并对相应的抗癌机制研究提供 线索和启示. 初步研究了该水溶性体系与 DNA 及氨基酸物种存在相互作用, 详细 研究还在进行中.

\section{紊文 融}

[1] Köpf-Mainer, H. and Köpf, H., Chem. Rev.. 87(1987), 1137.

[2] Toney, J. H., Brack, C.P. and Marks, T. J., J.Am. Chem. Soc., 108(1986), 7263.

王志强陆世维 胡皆汉 部和夫 (中国科学院大连化学物理研究所, 大连 116023)

- 国家自然科学基金资助项目. 